\title{
Expression of small heat shock-related protein 20 (HSP20) in rat myometrium is markedly decreased during late pregnancy and labour
}

\author{
B E Cross, H M O'Dea and D J MacPhee \\ Division of Basic Medical Sciences, Health Sciences Centre, Faculty of Medicine, Memorial University of \\ Newfoundland, Rm 5340B, 300 Prince Philip Drive, St John's, NL, Canada A1B 3 V6 \\ Correspondence should be addressed to D MacPhee; Email: dmacphee@mun.ca
}

\begin{abstract}
The underlying mechanisms regulating uterine contractions during labour are still poorly understood. Heat shock protein 20 (HSP20) is known to be present at high levels in smooth muscle and implicated in muscle relaxation, but HSP20 expression in the myometrium is completely undetermined. Since HSP20 has been implicated in smooth muscle relaxation, we hypothesized that HSP20 would be highly expressed in the rat myometrium during early and mid-pregnancy when the myometrium is relatively quiescent. Northern blot analysis particularly demonstrated that HSP20 mRNA detection was significantly decreased from day (d) 22 of pregnancy to 1-day post-partum (PP) compared with d6 $(P<0.05)$. HSP20 mRNA detection was also significantly decreased from d22 to d23 of gestation compared with non-pregnant (NP) samples. Immunoblot analysis showed that detection of HSP20 was significantly decreased at d23 compared with d12 and d15 $(P<0.05)$. HSP20 detection also significantly decreased at PP compared with $\mathrm{d} 15(P<0.05)$. Immunofluorescence analysis demonstrated that after $\mathrm{d} 15$, plasma membrane-associated localization of HSP20 decreased markedly in both circular and longitudinal muscle layers. In addition, HSP20 was detectable near cell membranes at much higher levels in the longitudinal muscle layer of progesterone-treated pregnant rats (delayed labour) at all gestational time points examined, compared with controls. Our results demonstrate that HSP20 mRNA and protein are highly expressed during early and mid-pregnancy and then the expression markedly decreases during late pregnancy and labour. The observed patterns of HSP20 expression are consistent with a potential role for HSP20 in facilitating myometrium quiescence during early and mid-pregnancy.

Reproduction (2007) 133 807-817
\end{abstract}

\section{Introduction}

The underlying mechanisms regulating uterine contractions during pregnancy and labour are still poorly understood. However, it is clear that the initiation of parturition is controlled by the integration of endocrine and mechanical (uterine stretch) signals which originate within the foetal genome (Lye et al. 2001). The combination of these signalling pathways leads to phenotypic changes in the myometrium, resulting in myometrial activation. Endocrine signalling requires the activation of a cascade which involves the foetal hypothalamic-pituitary-adrenal axis. This endocrine cascade yields, in most species, an increase in circulating oestrogen levels and a decrease in circulating progesterone levels in the maternal plasma (Challis et al. 2002). Although important, complete activation would not occur with the influence of the endocrine pathway alone. Mechanical signals imparted by uterine stretch (as a result of foetal growth during pregnancy) are also required for myometrial activation (Ou et al. 1997).

The result of activation is a switch from a muscle, which is quiescent during the majority of pregnancy, to one which is spontaneously active, excitable and highly responsive to uterotonic stimuli (Challis et al. 2002). This activation leads to an increase in the expression of a cassette of genes known collectively as contractionassociated proteins, which include ion channels, gap junction proteins and the oxytocin receptor (Challis et al. 2002)

The small heat shock proteins (sHSPs) are a family of proteins which range in mass from 12 to $43 \mathrm{kDa}$ and exhibit chaperone activity, participating in the folding of proteins in both normal and extreme conditions such as heat shock, oxidation and exposure to toxins such as anti-cancer drugs (Gusev etal.2002, 2005). These proteins also possess other common properties, including the presence of an 
80-residue conserved $\alpha$-crystallin domain, which spans two putative actin-binding domains (Gusev et al. 2005).

HSP2O is expressed practically in all tissues, but reaches a maximal level of $1.3 \%$ of total proteins in skeletal and smooth muscle (Bukach et al. 2003). This $20 \mathrm{kDa}$ protein can be phosphorylated by both CAMP- and cGMPdependent protein kinases (PKA/PKG) and increases in phosphorylation are associated with smooth muscle relaxation (Beall et al. 1999). Beall et al. (1999) have shown that the introduction of phosphopeptide analogues of HSP20 into bovine carotid artery smooth muscle inhibited agonist-induced muscle contractions. Upon phosphorylation, HSP20 has been shown to associate with actin (Rembold et al. 2000) and the actin-binding protein $\alpha$-actinin (Tessier et al. 2003), which is located at focal adhesions in smooth muscle cells. Amino acid residues 110-121 of HSP20 bear sequence homology with the actin-binding region of both cardiac and skeletal troponin I and this region is necessary for binding of HSP20 to actin filaments (Rembold et al. 2000). This binding is believed to inhibit cross-bridge cycling (myosin-actin interactions), thus leading to relaxation of smooth muscle (Rembold et al. 2001). The HSP20 has been shown in both skeletal and smooth muscle to exist in macromolecular aggregates with HSP27, another sHSP that we have identified as a candidate contraction-associated protein in the myometrium (White et al. 2005). This interaction is thought to be a functional one, with HSP20 regulating the function of HSP27 (Brophy et al. 1999).

The apparent importance of HSP20 in smooth muscle contraction, coupled with its interaction with the potential contraction-associated protein HSP27, led us to the hypothesis that HSP20 would be expressed in the rat myometrium during early and mid-pregnancy, but that its expression would be down-regulated during the late stages of pregnancy, as the muscle becomes activated and the onset of labour approaches.

\section{Materials and Methods}

\section{Animals}

Sprague-Dawley rats were obtained from the Mount Scio Vivarium (Memorial University of Newfoundland, St John's, NL, Canada). Animals were held and cared for under standard environmental conditions (12 h light: $12 \mathrm{~h}$ darkness) in the Animal Care Unit at the Health Sciences Centre, Memorial University of Newfoundland. Rats were fed LabDiet Prolab RMH 3000 (PMI Nutrition International, Brentwood, MO, USA) and water was available ad libitum. All experiments were approved by the institutional animal care committee under animal care protocols 02-02-DM to 06-02-DM. Virgin female rats ( $220 \mathrm{~g}$ each) were mated with stud males, and observation of vaginal plugs in the following morning was designated day 1 of pregnancy. The time of delivery under these standard conditions was day 23 of gestation.

\section{Experimental design}

Normal pregnancy and term labour

Individual animals were each placed in an euthanasia chamber and exposed to an increasing concentration of carbon dioxide gas resulting in death within 5-10 min. Tissues were collected at the following time points: nonpregnant (NP), gestation days (d) 6, 12, 15, 17, 19, 21, 22, 23 (labour) and 1-day post-partum (PP). Labour samples were taken during active labour and only after the rat had delivered two to three pups.

\section{Progesterone-delayed labour}

The onset of labour is coupled with a withdrawal of the inhibitory effects of progesterone on the myometrium following a decline in plasma levels of this steroid. To determine whether progesterone withdrawal might modulate HSP20 expression, pregnant rats were given either a daily injection of progesterone $(4 \mathrm{mg}$ s.c. in $0.2 \mathrm{ml}$ of corn oil) to maintain elevated plasma levels of this steroid, or vehicle alone $(0.2 \mathrm{ml}$ corn oil, s.c.) beginning on d20 of gestation. Individual animals were each placed in an euthanasia chamber and exposed to an increasing concentration of carbon dioxide gas resulting in death within 5-10 min. Samples were collected from vehicle control animals on $\mathrm{d} 21, \mathrm{~d} 22$ and $\mathrm{d} 23$ (during delivery), while samples were collected from progesterone-treated rats on d21, d22, d23 and d24; however, on d23 and d24, the rats were not in labour.

\section{Tissue collection}

For northern and immunoblot analyses, uterine horns were removed, opened longitudinally and fetuses and placentae discarded. Uterine tissue was placed in ice-cold PBS ( $\mathrm{pH}$ 7.4) and endometrial tissue was removed by gentle scraping with a scalpel blade. All myometrium samples were flash-frozen in liquid nitrogen and stored at $-80{ }^{\circ} \mathrm{C}$. For immunocytochemistry, rat uterine tissue samples were fixed in $4 \%$ paraformaldehyde in PBS ( $\mathrm{pH}$ 7.4) overnight at room temperature with shaking. The tissues were paraffin-embedded, sectioned and mounted on microscope slides by the Histology Unit of Memorial University of Newfoundland School of Medicine. Sections of rat uterine tissue contained both longitudinal and circular smooth muscle layers and sections were processed under identical conditions and at the same time in each experiment.

\section{Northern blot analysis}

\section{RNA isolation}

Northern blot analysis for both normal pregnancy and delayed labour regimes was performed on four separate, independent sets of RNA samples $(n=4$; i.e. four rats used per gestational time point). RNA was isolated from 
tissues using TRIzol Reagent (Invitrogen Corporation) exactly according to the manufacturer's instructions. RNA quality and quantity $\left(\mathrm{A}_{260 / 280}\right)$ were determined using a Shimadzu Bio-Mini Spectrophotometer (Mandel Scientific, Guelph, ON, Canada) and samples were stored at $-70{ }^{\circ} \mathrm{C}$.

\section{Electrophoretic separation and capillary transfer of RNA}

RNA samples (10 $\mu$ g per lane) were loaded on a $1 \%$ agarose gel containing $0.66 \mathrm{M}$ formaldehyde and $1 \times$ MOPS buffer (0.02 M MOPS $\mathrm{pH}=7.0,2 \mathrm{mM}$ sodium acetate, $10 \mathrm{mM}$ EDTA $\mathrm{pH}=8.0$ ) and electrophoretically separated at $80 \mathrm{~V}$ in $1 \times$ MOPS/0.22 $\mathrm{M}$ formaldehyde running buffer. RNA was transferred overnight to a nylon membrane (Hybond-XL; Amersham Pharmacia Biotech) by upward capillary action using $2 \times$ SSC $(0.3 \mathrm{M}$ sodium chloride, $0.03 \mathrm{M}$ sodium citrate) in DEPC-treated $\mathrm{dd}_{2} \mathrm{O}$. RNA was cross-linked to nylon membrane with a UVC-508 u.v. cross-linker (Ultra-Lum Inc., Paramount, CA, USA) and all blots were stored at $-20{ }^{\circ} \mathrm{C}$ until required.

\section{Northern blot hybridization}

Northern blot hybridization procedures have been described in detail elsewhere (White et al. 2005, Williams et al. 2005). Briefly, membranes were prehybridized in hybridization buffer, then hybridized overnight at $42{ }^{\circ} \mathrm{C}$ in hybridization buffer containing a ${ }^{32}$ P-labelled HSP20 cDNA probe. The $729 \mathrm{bp}$ Bam HI/Xba I fragment of the rat HSP20 cDNA (Genbank accession no. NM_138887) was kindly provided, within the vector pRTL2, by Dr Colleen Brophy and Dr Charles Robb Flynn (Arizona State University, Tempe, AZ, USA). Radiolabelled cDNA probes were prepared with a Megaprime DNA Labelling Kit (Cat. No. RPN 1607; Amersham Biosciences) according to manufacturer's specifications. Following hybridization, blots were washed in $2 \times \mathrm{SSC} / 0.1 \%$ SDS and exposed to X-ray film (Hyperfilm MP; Amersham Pharmacia Biotech), with the exception of the delayed labour experiments where blots were exposed to multisensitive phosphor imaging screens (cyclone storage phosphor screen; Perkin Elmer, Boston, MA, USA). Multiple exposures were produced for each northern blot to ensure that the results were within the linear range of the film or screens.

Following the analysis of HSP20 gene expression, northern blots were stripped by incubating the membranes in a solution of $1 \mathrm{M}$ Tris-Cl, $1 \mathrm{mM}$ EDTA, $0.1 \times$ Denhardt's solution in $\mathrm{ddH}_{2} \mathrm{O}$. Membranes were washed at room temperature with $0.1 \times \mathrm{SSPE}$ and then subsequently analysed for expression of $18 \mathrm{~S}$ rRNA using the same procedures described previously. A $750 \mathrm{bp}$ EcoRI fragment of the rabbit $18 \mathrm{~S}$ ribosomal cDNA (Genbank Accession: X06778) was generously provided, within the vector pBluescript, by Dr I Skerjanc (University of Western Ontario, London, Ontario,
Canada; Petropoulos \& Skerjanc 2002, Rogerson et al. 2002). 18S rRNA is constitutively expressed in rat myometrial cells and has been utilized as a loading control for analysis of myometrial gene expression (Oldenhof et al. 2002, Shynlova et al. 2004, White et al. 2005, Williams et al. 2005).

\section{Immunoblot analysis}

Immunoblot analysis for both normal pregnancy and delayed labour experiments was performed on four separate, independent sets of protein samples $(n=4$; i.e. four rats used per gestational time point) according to the method described by MacPhee \& Lye (2000). Briefly, frozen rat myometrial samples were pulverized under liquid nitrogen and homogenized in RIPA lysis buffer (50 mM Tris- $\mathrm{HCl}(\mathrm{pH} 7.5), 150 \mathrm{mM} \mathrm{NaCl}, 1 \%$ (vol/vol) Triton $\mathrm{X}-100,1 \%(\mathrm{wt} / \mathrm{vol})$ sodium deoxycholate and $0.1 \%$ (wt/vol) SDS) containing $100 \mu \mathrm{M} \mathrm{Na} \mathrm{Na}_{3}$ and Complete, Mini EDTA-free protease inhibitors (Roche Molecular Biochemicals). Samples were centrifuged at $15000 \mathrm{~g}$ at $4{ }^{\circ} \mathrm{C}$ for $15 \mathrm{~min}$, and the supernatants were collected. Protein concentrations were determined by the Bradford assay (Bradford 1976) using Bio-Rad protein assay dye reagent (Bio-Rad Laboratories) and protein samples $(100 \mu \mathrm{g} /$ lane) were separated by PAGE in $12 \%$ resolving gels according to the method described by Laemmli (1970). The gels were electroblotted to BioTrace NT nitrocellulose membranes (Pall Life Sciences, Pensacola, FL, USA).

Membranes were rinsed in Tris-buffered salineTween-20 (TBST; $20 \mathrm{mM}$ Tris base, $137 \mathrm{mM} \mathrm{NaCl}$ and $0.1 \%$ Tween-20; $\mathrm{pH} 7.6$ ) and blocked in $5 \%$ milk powder/TBST for $45 \mathrm{~min}$. Unless otherwise stated, all incubations were performed at room temperature and with constant agitation. Rabbit polyclonal antisera raised against HSP20 (Cat. No. 07-490; Upstate Biotechnology, Lake Placid, NY, USA) or mouse monoclonal antisera raised against smooth muscle calponin (Cat. No. C2687; clone hCP; Sigma-Aldrich) used at dilutions of 1:2000 and 1:50 000 respectively were incubated with the blots for $1 \mathrm{~h}$ and then they were rinsed with TBST. Horseradish peroxidase $(\mathrm{HRP})$-conjugated goat anti-rabbit $\operatorname{lgG}(\mathrm{H}+\mathrm{L})$ or HRP-conjugated goat anti-mouse $\operatorname{lgG}(\mathrm{H}+\mathrm{L})$ (Cat. No. 31460 and 31430 respectively; Pierce, Rockford, IL, USA) were used as secondary antisera at dilutions of 1:10 000 and 1:150 000 respectively. Proteins were detected using the Pierce SuperSignal West Pico chemiluminescent substrate detection system (MJS Biolynx, Inc., Brockville, Ontario, Canada) and multiple exposures were produced to ensure the linearity of the film exposures.

Following the detection of HSP20, all blots were stripped with Restore western blot stripping solution (Pierce) according to the manufacturer's instructions. Analysis of calponin protein expression was subsequently performed. We have determined that calponin 
protein is constitutively expressed in non-pregnant and pregnant rat myometrial tissue under our protein extraction conditions (i.e. RIPA buffer extraction protocol) and, as a result, serves as a sufficient loading control for our analyses (White et al. 2005, Williams et al. 2005).

\section{Immunocytochemistry}

Two separate, independently collected sets of rat tissues $(n=2$; i.e. 2 rats used per gestational time point) were utilized for immunocytochemistry experiments and the experiments were repeated thrice. Following de-waxing and rehydration, tissue sections were permeabilized with $0.125 \%$ trypsin in PBS for 10 min at room temperature and then rinsed with PBS. Unless otherwise noted, all incubations were performed at room temperature and with constant agitation. Tissue sections were blocked with $5 \%$ normal goat serum $/ 1 \%$ horse serum in PBS for $30 \mathrm{~min}$. The sections were then incubated overnight with constant agitation at $4{ }^{\circ} \mathrm{C}$ in rabbit anti-HSP20 (Cat. No. H183048D; US Biological, Swampscott, MA, USA) at a dilution of 1:200 in blocking solution or rabbit IgG (Cat. No. 011-000003; Jackson ImmunoResearch Labs, Inc., West Grove, PA, USA) at the same final concentration to serve as a negative control. Tissue sections were washed in PBS and then incubated in fluorescein isothiocyanate-conjugated sheep anti-rabbit IgG (Cat. No. F7512; Sigma-Aldrich) at a dilution of 1:200 in blocking solution for $30 \mathrm{~min}$. For nuclear staining, TO-PRO-3 iodide (Cat. No. T3605; Molecular Probes, Eugene, OR, USA) was added at a dilution of 1:250 to the secondary antibody solution. The sections were washed with cold PBS containing $0.02 \%$ Tween-20, followed by mounting in Vectashield (Vector Laboratories Inc., Burlington, Ontario, Canada). Prepared slides were observed and images were collected with an Olympus Fluoview laser scanning confocal microscope (Olympus Optical Company Ltd, Melville, NY, USA). For each immunocytochemistry experiment (i.e. normal pregnancy and term labour, progesterone-delayed labour) image collection parameters (PMT (photomultiplier tube), gain and black level settings) were the same within each muscle layer.

\section{Data analysis}

Densitometric analysis of northern and immunoblots was performed with the aid of Scion Image software (Scion Image Corporation, Frederick, MD, USA). Densitometric measurements of HSP20 mRNA were normalized to those of $18 \mathrm{~S}$ rRNA while measurements of HSP20 protein on immunoblots were normalized to those of calponin. Statistical analysis was performed with GraphPad Instat version 3.0 (GraphPad Software, San Diego, CA, USA, www.graphpad.com) and data graphed using GraphPad Prism version 4.0 (GraphPad Software). Data from northern and immunoblot analyses of HSP20 expression during normal gestation were subjected to a one-way ANOVA and a Tukey-Kramer multiple comparisons test. Data from analysis of HSP20 expression during progesterone-delayed labour were subjected to a two-way ANOVA and a Bonferroni post-test. Values were considered significantly different if $P<0.05$.

\section{Results}

\section{Normal pregnancy and labour}

\section{Expression of HSP2O mRNA and protein}

To characterize the levels of HSP20 mRNA within myometrial samples, northern blots of myometrial total RNA from NP, d6, d12, d15, d17, d19, d21, d22, d23 and PP were analysed with radiolabelled probes generated from a rat HSP20-specific cDNA (Fig. 1A). Our experiments demonstrated that HSP20 mRNA detection significantly decreased during late gestation

A

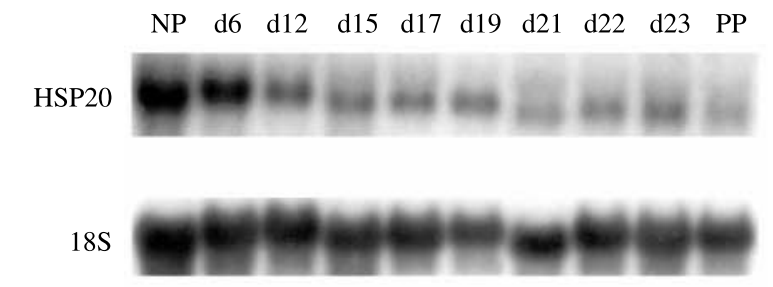

B

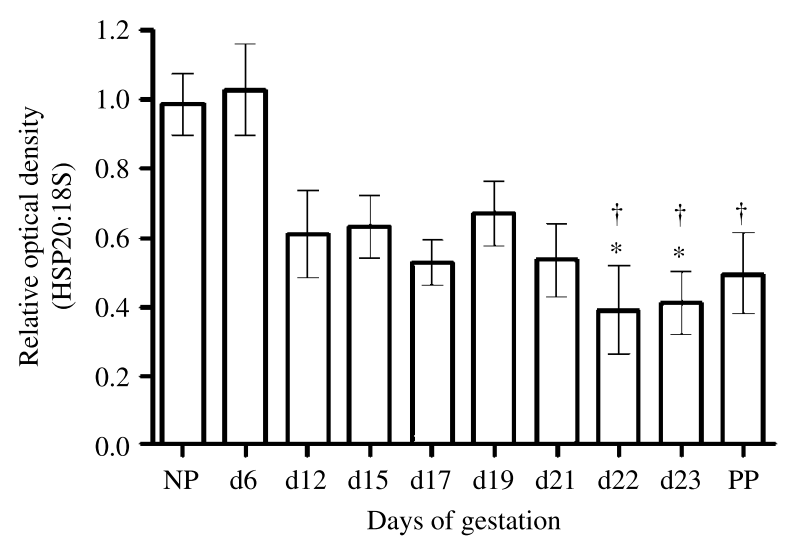

Figure 1 Northern blot analysis of HSP20 mRNA detection in rat myometrium during pregnancy, labour and 1-day post-partum. A: Representative northern blots of HSP20 mRNA detection and $18 \mathrm{~S}$ rRNA detection. Analysis was performed using an HSP20-specific rat cDNA and an 18S-specific rabbit cDNA as templates for radiolabelled probe production. Ten micrograms of total RNA were utilized per lane. B: Densitometric analysis illustrating the decrease in HSP20 mRNA detection during pregnancy and labour. Detection levels on d22, d23 were significantly decreased $\left({ }^{*} P<0.05\right)$ when compared with NP and values on $\mathrm{d} 22$ to PP were significantly decreased $\left({ }^{\top} P<0.05\right)$ when compared with d6. Values are from four independent experiments $(n=4) \pm$ s.E.M. Days 6, 12, 15, 17, 19, 21, 22 and 23 represent gestational time points. NP, nonpregnant; PP, 1-day post-partum. 
(one-way ANOVA, $P<0.05 ; n=4$ ). Specifically, HSP20 was highly detectable in NP and d6 samples, then detection appeared to decrease by d12. HSP20 mRNA detection was significantly decreased at $\mathrm{d} 22$ and $\mathrm{d} 23$ when compared with NP samples and between $\mathrm{d} 22$ and PP, inclusive, when compared with d6 samples (Tukey-Kramer post-test, $P<0.05$; Fig. $1 \mathrm{~A}$ and $\mathrm{B}$ ).

Immunoblot analysis using HSP20-specific antisera demonstrated that HSP20 detection decreased significantly during late gestation (one-way ANOVA, $P<0.05 ; n=4)$. Protein detection levels remained high until d15 of gestation and then began to decrease thereafter. Detection levels at d23 were significantly lower than those at d12 and d15, while PP levels were significantly decreased compared with d15 samples (Tukey-Kramer post-test, $P<0.05$; Fig. 2A and B).

\section{Immunocytochemical detection of HSP2O}

Detection of HSP20 in the longitudinal muscle layer demonstrated that HSP20 was primarily localized at or near cell membranes from NP and throughout gestation (Figs 3 and 4). The level of detection gradually decreased

A $\begin{array}{llllllllll}\text { NP } & \text { d6 } & \text { d12 } & \text { d15 } & \text { d17 } & \text { d19 } & \text { d21 } & \text { d22 } & \text { d23 } & \text { PP }\end{array}$ HSP20 Calp

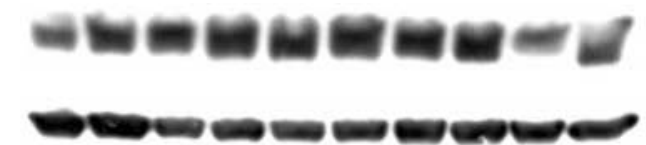

B

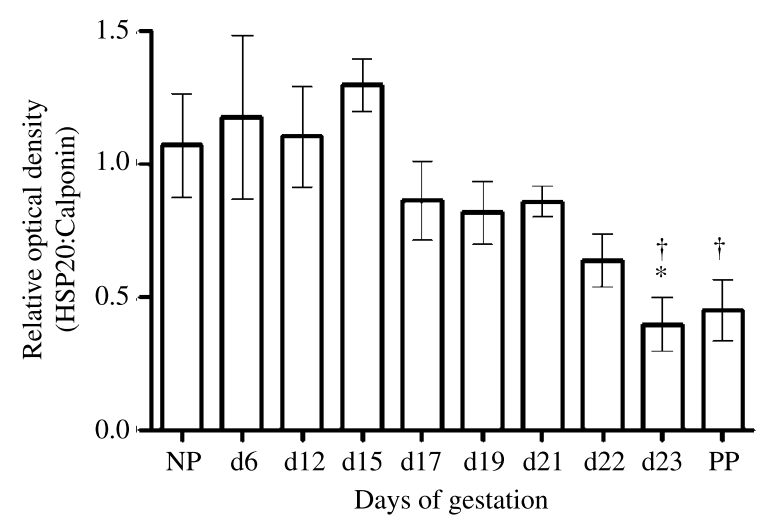

Figure 2 Immunoblot analysis of HSP20 protein detection in rat myometrium during pregnancy, labour and 1-day post-partum. A: Representative immunoblots of HSP20 protein and calponin detection. B: Densitometric analysis illustrating the decrease in HSP20 protein detection during pregnancy and labour. Values on $\mathrm{d} 23$ were significantly decreased $\left({ }^{*} P<0.05\right)$ when compared with d12 and values on $\mathrm{d} 23$, PP were significantly decreased $\left({ }^{\dagger} P<0.05\right)$ when compared with $\mathrm{d} 15$. Values are from four independent experiments $(n=4) \pm$ s.E.M. Days 6, 12, 15, 17, 19, 21, 22 and 23 represent gestational time points. NP, nonpregnant; PP, 1-day post-partum.
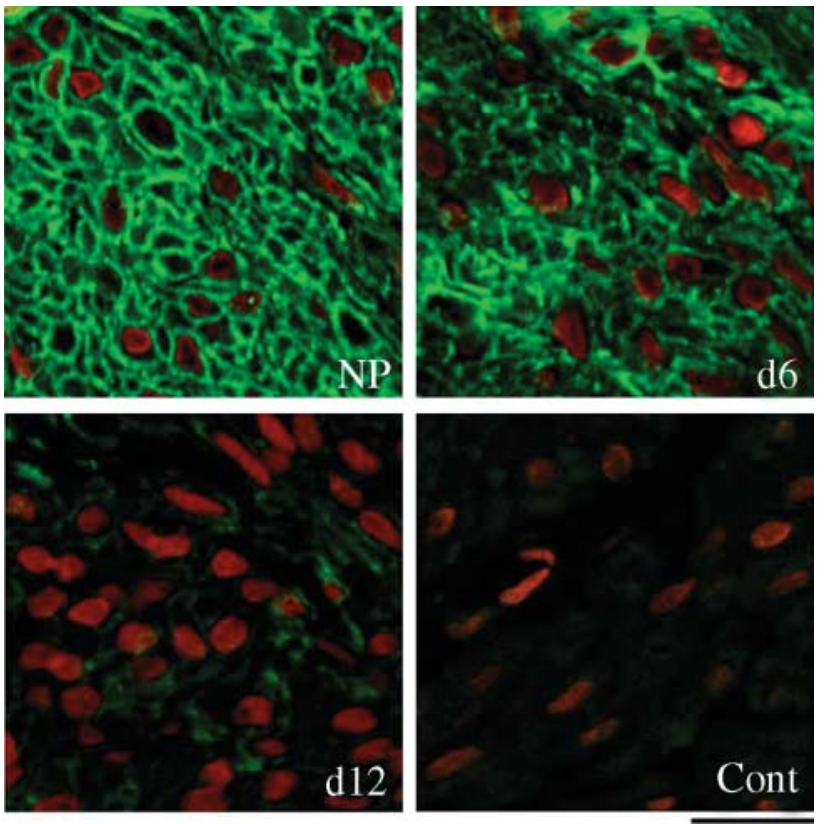

Figure 3 Immunocytochemical analysis of HSP20 protein detection in the longitudinal smooth muscle layer of rat myometrium between NP and d12 of pregnancy using polyclonal rabbit anti-HSP20 antisera.

These images demonstrate the observed localization of HSP2O (green) at or near the cell membrane. TO-PRO-3 iodide was used for nuclear staining (red). Cont, control, rabbit IgG. Scale bar $=50 \mu \mathrm{m}$.

throughout gestation, reaching its lowest detection level in the PP samples; however, detection was lower on d12 than at the adjacent $\mathrm{d} 6$ and $\mathrm{d} 15$ time points. A similar pattern of down-regulation of HSP20 detection was seen in the circular muscle layer (Figs 5 and 6). Although HSP20 appeared to be localized at or near cell membranes, there was also evidence of HSP20 detection in the cytoplasm.

\section{Progesterone-induced delayed labour}

\section{Expression of HSP2O mRNA and protein}

Throughout the majority of pregnancy, circulating levels of progesterone in the rat are high, reaching peak levels between $\mathrm{d} 15$ and $\mathrm{d} 19$ then declining thereafter including at labour (Lye et al. 1993). The finding that HSP20 expression also decreased significantly during late gestation and labour suggested that the decline in progesterone levels and its subsequent effects on the myometrium might be responsible, at least in part, for our results. Animals treated with progesterone beginning on d20 of gestation did not enter labour on d23. Our experiments demonstrated that, at each time point, there were no significant differences in HSP20 mRNA detection levels between the progesterone- and vehicle-treated animals (two-way ANOVA, $P>0.05 ; n=3$; Fig. 7). Immunoblot analysis also demonstrated that there were no significant differences in HSP20 protein detection levels (two-way ANOVA, $P>0.05 ; n=4$; Fig. 8). 

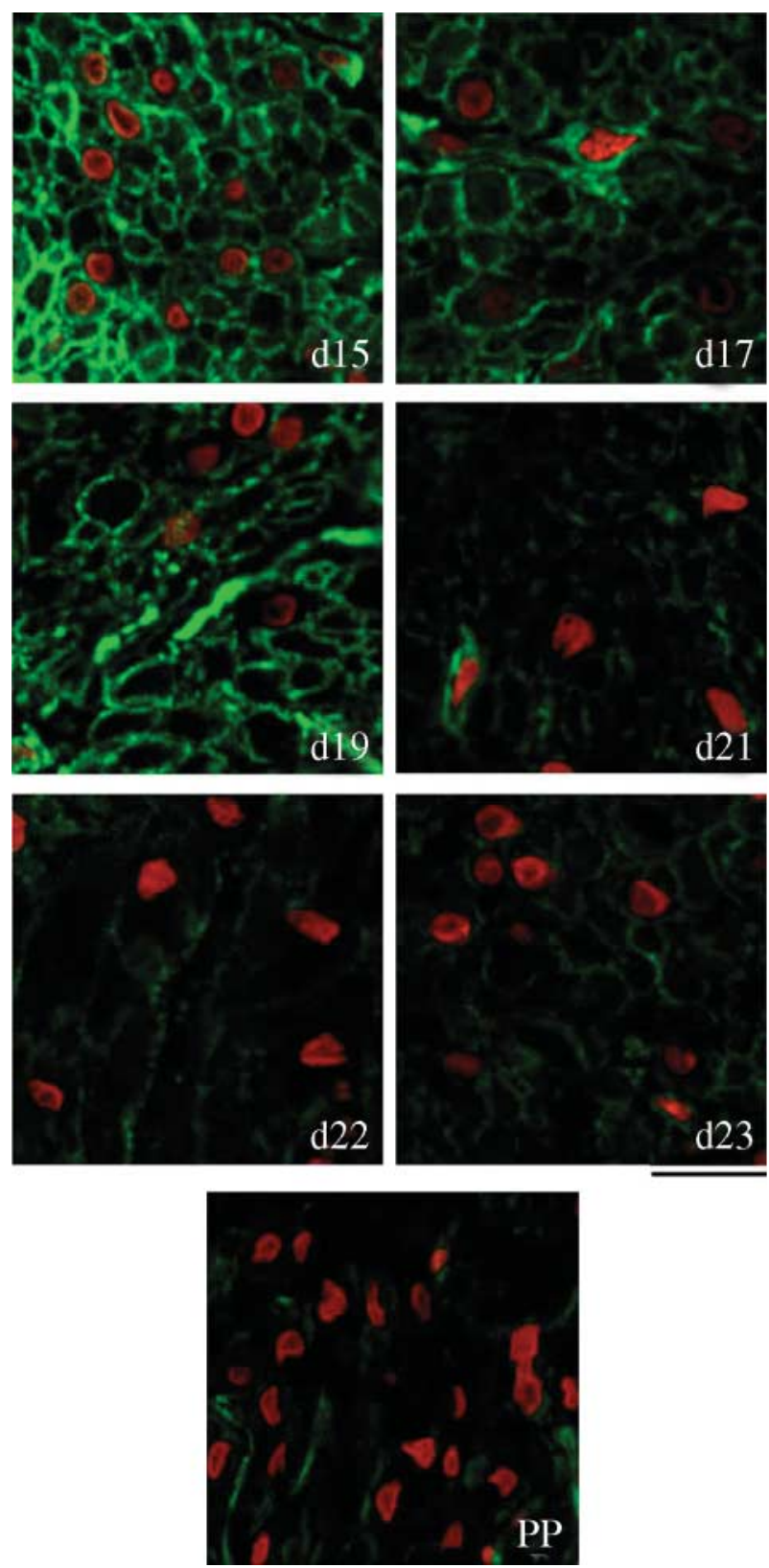

Figure 4 Immunocytochemical analysis of HSP20 protein detection in the longitudinal smooth muscle layer of rat myometrium between d15 of pregnancy and PP using polyclonal rabbit anti-HSP20 antisera (green). TO-PRO-3 iodide was used for nuclear staining (red). Scale bar $=50 \mu \mathrm{m}$.

\section{Immunocytochemical detection of HSP2O}

There was a striking difference in detection levels between progesterone-treated and vehicle control tissue samples in the longitudinal muscle layer (Fig. 9). HSP20 detection in the progesterone-treated samples was markedly higher than that of the vehicle controls at all examined gestational time points. In both cases, HSP20 was also localized at or near cell membranes. In the circular muscle layer, no marked differences in HSP20 detection levels or spatial
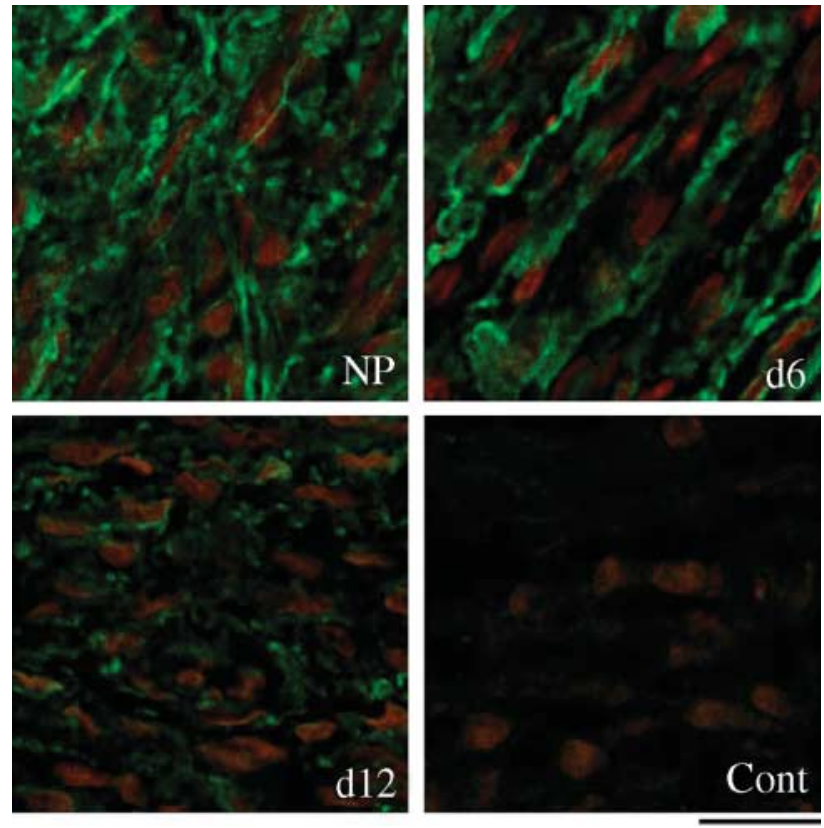

Figure 5 Immunocytochemical analysis of HSP20 protein detection in the circular smooth muscle layer of rat myometrium between NP and d12 of pregnancy using polyclonal rabbit anti-HSP20 antisera (green). TO-PRO-3 iodide was used for nuclear staining (red). Scale bar $=50 \mu \mathrm{m}$.

localization were observed between the progesteronetreated and vehicle control samples (Fig. 10).

\section{Discussion}

We recently reported that HSP27 was highly expressed in the rat myometrium during pregnancy and postulated that it could be a contraction-associated protein (White et al. 2005). Until now the expression of no other sHSP had been reported in the rat myometrium during pregnancy. HSP20, highly expressed in smooth muscle (Bukach et al. 2003), may have a role in smooth muscle relaxation (Beall et al. 1999), and can exist in macromolecular aggregates with HSP27 (Brophy et al. 1999). Therefore, we hypothesized that HSP20 would be expressed in the rat myometrium during early and mid-pregnancy, but that its expression would be down-regulated during the late stages of pregnancy, as the muscle became activated and the onset of labour approached.

\section{Normal pregnancy and labour}

Our northern blot analysis showed that the detection of HSP20 mRNA decreased significantly from d22 to PP, while detection of HSP20 protein on immunoblots showed a significant decrease by labour. Thus, the observed decrease in HSP20 protein expression could be the result of decreased HSP20 mRNA available for subsequent translation. Together with our results from immunofluorescence experiments demonstrating a marked reduction in HSP20 immunostaining after d15, 

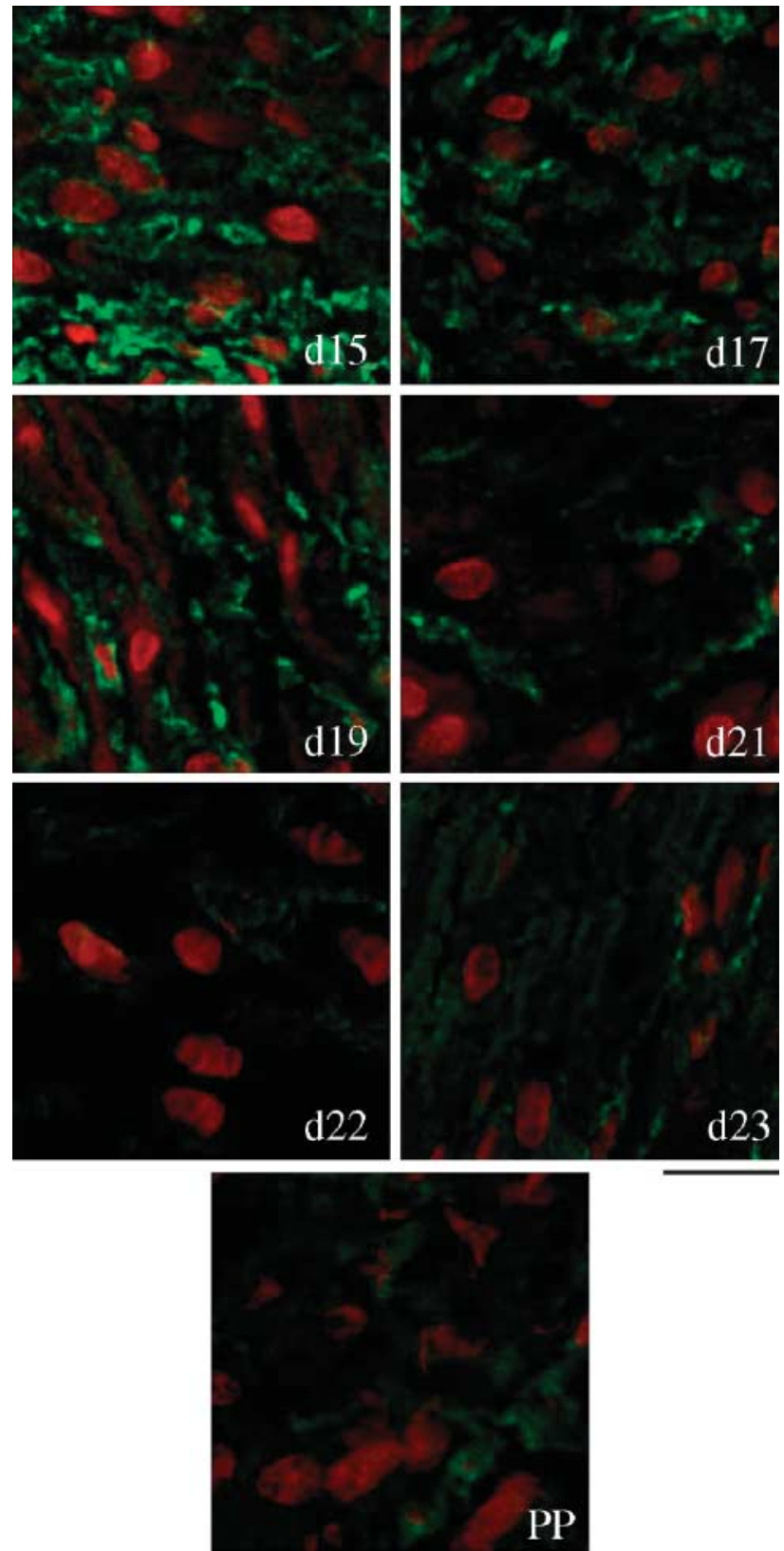

Figure 6 Immunocytochemical analysis of HSP20 protein detection in the circular smooth muscle layer of rat myometrium between $\mathrm{d} 15$ of pregnancy and PP using polyclonal rabbit anti-HSP20 antisera (green). TO-PRO-3 iodide was used for nuclear staining (red). Scale bar $=50 \mu \mathrm{m}$.

the observed patterns of HSP20 expression during pregnancy and labour potentially support a role for HSP20 in regulating myometrial quiescence during early and mid-pregnancy. Previous research in smooth muscle has demonstrated an association between HSP20 and actin, which has been suggested to lead to actin depolymerization and inhibition of contraction (Beall et al. 1999, Tessier et al. 2004, Dreiza et al. 2005). A decrease in HSP20 expression late in gestation could also lead to a decrease in the association of HSP20 with actin thereby relieving, at least in part, contractile
A

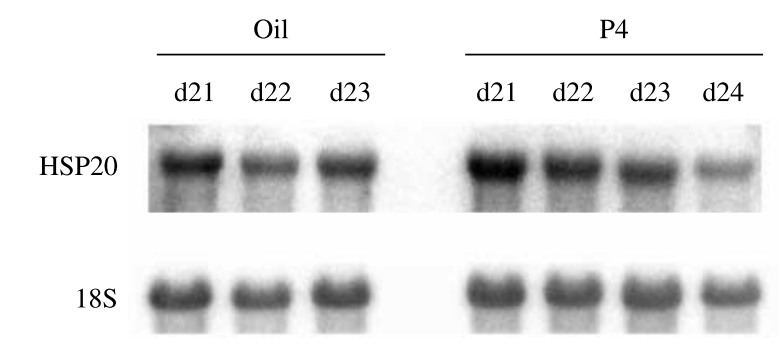

$\mathrm{B}$

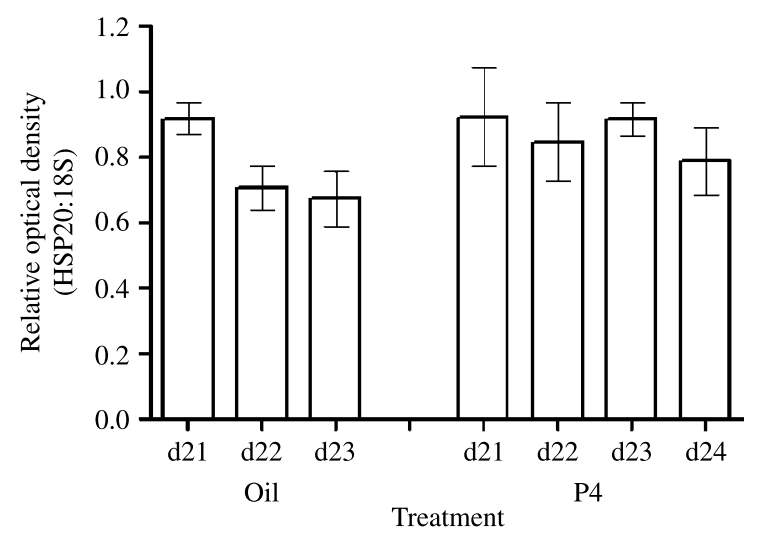

Figure 7 Northern blot analysis of HSP20 mRNA detection in a delayedlabour model following administration of progesterone or corn oil (vehicle control) to pregnant rats. A: Representative northern blots of HSP20 mRNA detection and 18S rRNA detection. B: Densitometric analysis illustrating no significant change in the level of detection between treatment groups. Values are from three independent experiments $(n=3) \pm$ S.E.M. P4, progesterone. Designations 21-Oil, 22-Oil, 23-Oil, 21-P4, 22-P4, 23-P4, 24-P4 represent gestational time points in the two treatment groups.

inhibition of the myometrium. Significant rat uterine contractile activity only becomes evident within the last $24 \mathrm{~h}$ prior to labour (Buhimschi \& Garfield 1996, Buhimschi et al. 1998).

Immunocytochemistry experiments revealed that HSP20 was primarily localized at or near cell membranes. HSP20 has been shown to be associated with the actinbinding protein $\alpha$-actinin, which is a known component of focal adhesions (or dense plaques) in smooth muscle cells (Tessier et al. 2003). Furthermore, the spatial immunolocalization of HSP20 correlates, at least in part, with Serine 15 (Ser15) phosphorylated HSP27 expression, as Ser15- phosphorylated HSP27 was also localized to cell membranes prior to labour (White et al. 2005). The significance of this finding is not yet clear, but Fuchs et al. (2000) has demonstrated that phosphorylated HSP27 can inhibit phosphorylation of HSP20 leading to reduction of vascular smooth muscle relaxation. In total, our findings are consistent with a report that HSP20 and HSP27 proteins may exist in aggregates in smooth muscle (Brophy et al. 
A

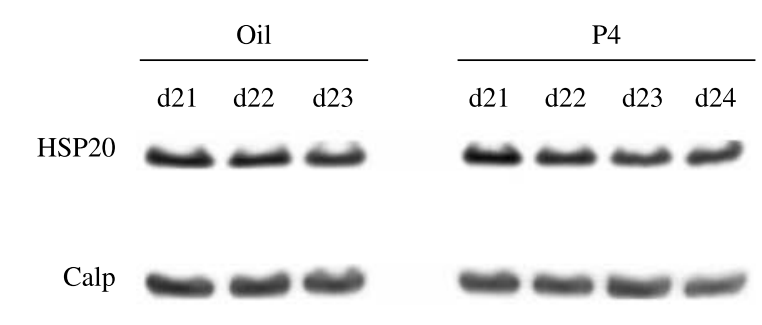

B

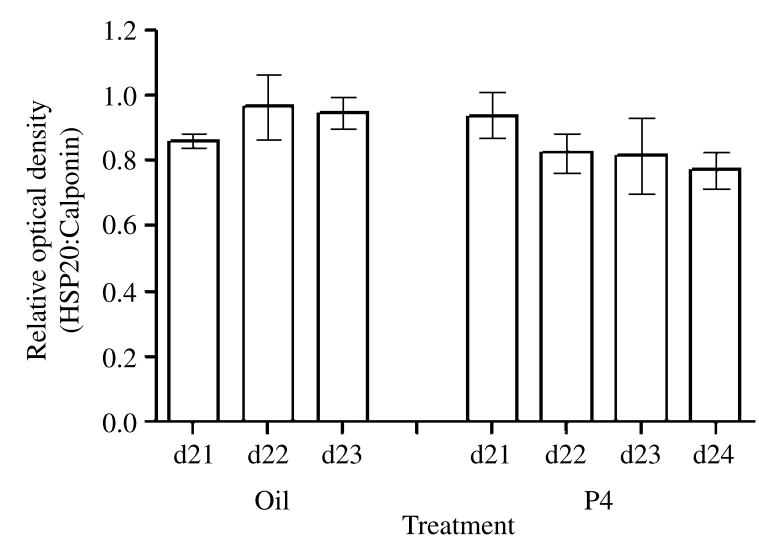

Figure 8 Immunoblot analysis of HSP20 protein detection in a delayedlabour model following administration of progesterone or corn oil (vehicle control) to pregnant rats. A: Representative immunoblots of HSP20 and calponin detection. B: Densitometric analysis illustrating no significant change in the level of detection between treatment groups. Values are from four independent experiments $(n=4) \pm$ s.E.M. P4, progesterone. Designations 21-Oil, 22-Oil, 23-Oil, 21-P4, 22-P4, 23-P4, 24-P4 represent gestational time points in the two treatment groups.

1999) and our future work will examine the phosphorylation state of HSP20 in the myometrium during gestation and the interdependence of HSP20 and HSP27 in uterine smooth muscle function.

Physiological growth of the pregnant uterus occurs by two mechanisms: an increase in cell number (hyperplasia) followed by an increase in cell size (hypertrophy; Shynlova et al. 2006). The transition between these two phases of growth is associated with a transient activation of the caspase cascade, at $\sim \mathrm{d} 12-\mathrm{d} 14$ of gestation, which initiates the differentiation of uterine smooth muscle but does not lead to the biochemical or morphological features of apoptosis (Shynlova et al. 2006). Interestingly, within relatively the same period, we observed a transient but marked decrease in immunodetection of HSP2O in both muscle layers by d12 of gestation followed by an increase in detection by d15. We believe these results may be related to the initiation of uterine smooth muscle differentiation. The subsequent increase in HSP20 detection by d15 in both muscle layers could be a reflection of a protective mechanism against cell death since HSP20 has
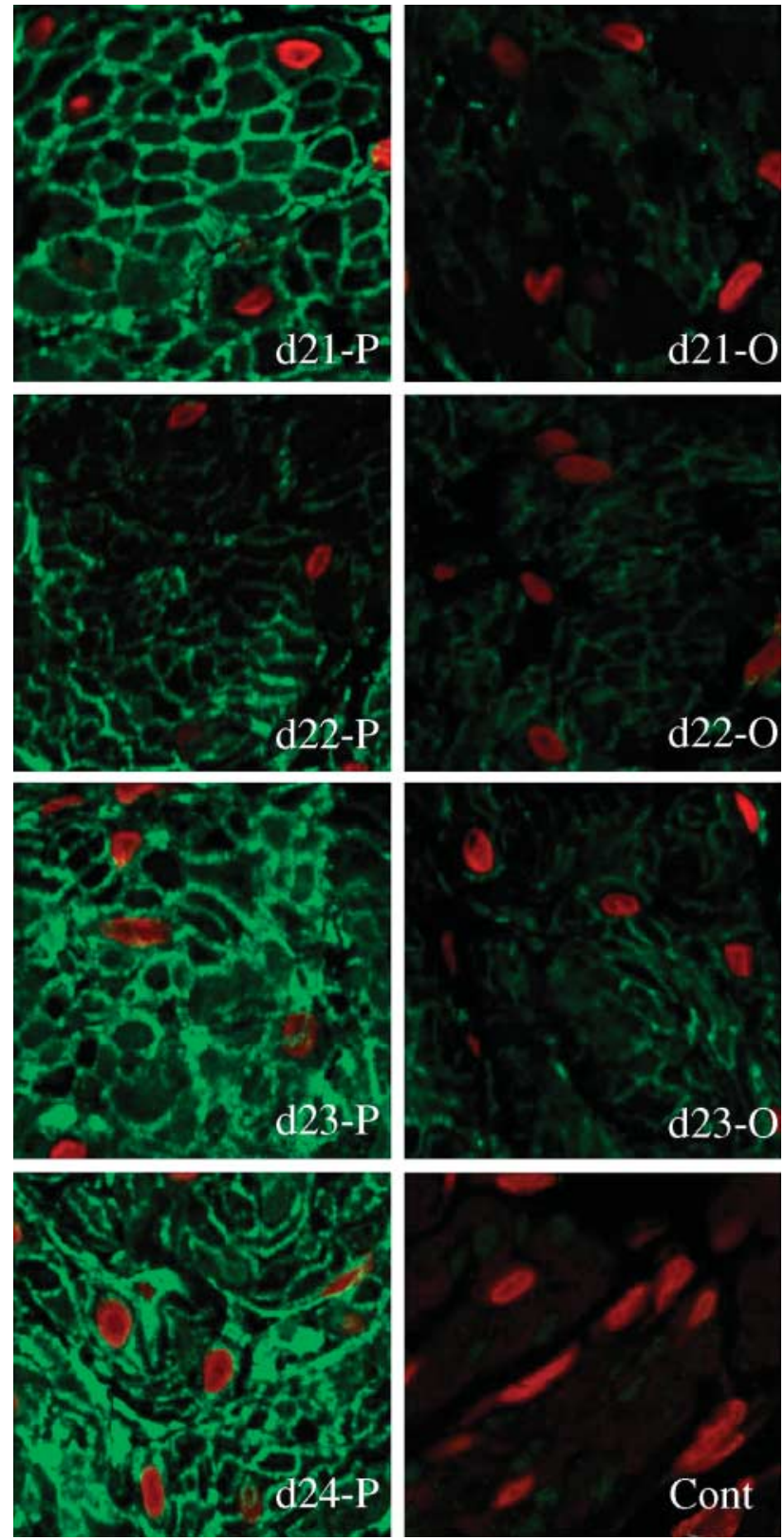

Figure 9 Immunocytochemical analysis of HSP20 protein (green) detection in the longitudinal smooth muscle layer of rat myometrium in a delayed-labour model following administration of progesterone $(4 \mathrm{mg}$ in $0.2 \mathrm{ml}$ corn oil, s.c.) or oil (vehicle control; $0.2 \mathrm{ml}$ corn oil, s.c.). These images illustrate the observed maintenance of HSP20 detection in the progesterone treatment samples. $\mathrm{P}$, progesterone; $\mathrm{O}$, oil; Cont, control, rabbit IgG. Days 21-O, 22-O, 23-O, 21-P, 22-P, 23-P, 24-P represent gestational time points. TO-PRO-3 iodide was used for nuclear staining (red). Scale bar $=50 \mu \mathrm{m}$.

previously been shown to protect against apoptosis in cardiomyocytes (Fan et al. 2004).

\section{Progesterone-induced delayed labour}

Circulating levels of progesterone in the rat peak at d19 of gestation declining thereafter including at labour 

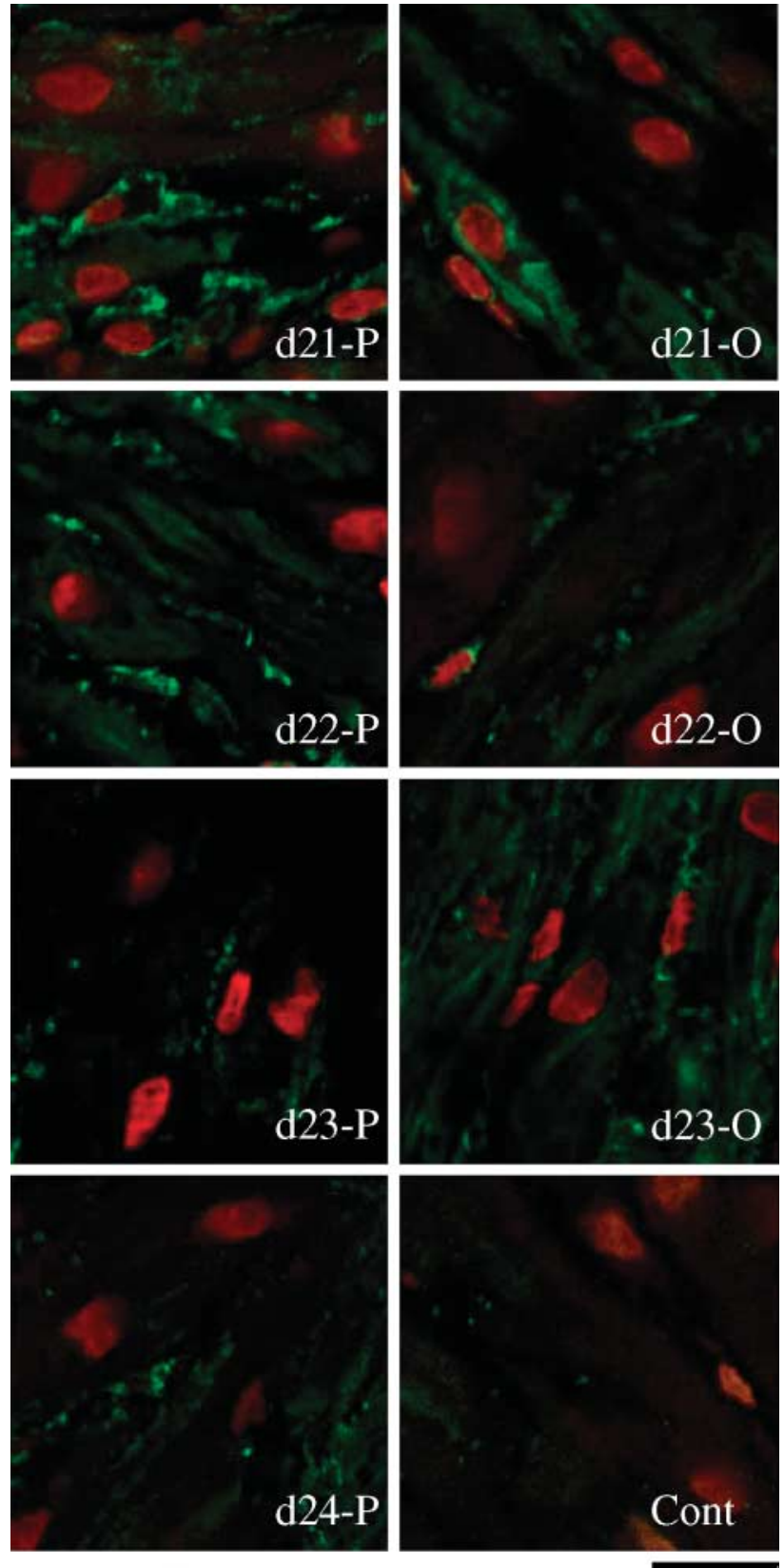

Figure 10 Immunocytochemical analysis of HSP20 protein (green) detection in the circular smooth muscle layer of rat myometrium in a delayed-labour model following administration of progesterone (4 mg in $0.2 \mathrm{ml}$ corn oil, s.c.) or oil (vehicle control; $0.2 \mathrm{ml}$ corn oil, s.c.). P progesterone; O, oil; Cont, control, rabbit IgG. Days 21-O, 22-O, 23-O, 21-P, 22-P, 23-P, 24-P represent gestational time points. TO-PRO-3 iodide was used for nuclear staining (red). Scale bar $=50 \mu \mathrm{m}$.

(Lye et al. 1993); thus, the observed drop in HSP20 expression late in pregnancy could be related to the decline in circulating levels of this steroid. Evidence suggests that expression of sHSPs can be regulated by both progesterone and oestrogen (Ciocca et al. 1993, Tabibzadeh et al. 1996, Bany \& Schultz 2001, Kato et al. 2002). Progesterone administration to pregnant rats did not result in significant induction of HSP20 mRNA and protein expression compared with vehicle controls as measured by northern and immunoblot analysis respectively. However, immunocytochemical analysis demonstrated a maintenance of HSP20 expression at or near cell membranes from $\mathrm{d} 21-\mathrm{d} 24$ in the longitudinal muscle layer of progesterone-treated rats compared with vehicle controls suggesting a regional sensitivity of HSP20 expression to progesterone. It has been reported that the longitudinal and circular muscle layers exhibit different contractile and physiological characteristics (Osa \& Katase 1975, Kawarabayashi \& Osa 1976, Chow \& Marshall 1981, Mlynarczyk et al. 2003); however, it is important to note that we demonstrated similar HSP20 immunolocalization patterns in the two muscle layers across normal gestation and particularly during early to mid-pregnancy when circulating levels of progesterone are high (Lye et al. 1993). Thus, the reason(s) for increased HSP20 expression from d21 to d24 in the longitudinal muscle layer during progesterone-induced delayed labour is unknown and requires future clarification. In total, our findings indicate that progesterone regulation of HSP20 expression, if any, may be quite complex. Future work will attempt to more specifically determine the role of both progesterone and oestrogen in the regulation of HSP2O gene expression.

\section{HSP20 expression and relevance to initiation of labour}

A recent study by Girotti \& Zingg (2003) using DNA microarrays of rat uterus has found that as the uterus progresses toward labour, the degree of gene suppression is greater than the degree of gene activation. This finding suggests that for the initiation of labour, the suppression of genes related to the control of quiescence may be equally as important as the up-regulation of the contraction-associated proteins. Our work has identified that HSP20 expression decreases as the uterus progresses toward labour. Although it is not yet possible to determine the specific functional role(s) of HSP20 in the rat myometrium during pregnancy and labour, our results, coupled with documented evidence of a role for HSP2O in smooth muscle relaxation, implicate a role for HSP20 in the regulation of myometrial quiescence. Subsequent down-regulation of HSP20 expression prior to and during labour may also be important for the initiation of parturition.

\section{Acknowledgements}

We would like to acknowledge the assistance of Judy Foote and Art Taylor for tissue processing and sectioning of rat myometrial tissue for our immunocytochemistry experiments. We also thank Dr Karen Mearow for critically reading the manuscript. The research described in this manuscript was funded by the 
Natural Sciences and Engineering Research Council of Canada, grant no. 250218-02 and aided by a New Opportunities Fund infrastructure grant from the Canada Foundation for Innovation (Project no. 74119). B E Cross and H M O'Dea were partially funded by Summer Undergraduate Research Awards from the Faculty of Medicine (Memorial University of Newfoundland). The authors declare that there is no conflict of interest that would prejudice the impartiality of this scientific work.

\section{References}

Bany BM \& Schultz GA 2001 Increased expression of a novel heat shock protein transcript in the mouse uterus during decidualization and in response to progesterone. Biology of Reproduction 64 284-292.

Beall A, Bagwell D, Woodrum D, Stoming TA, Kato K, Suzuki A, Rasmussen H \& Brophy CM 1999 The small heat shock-related protein, HSP20, is phosphorylated on serine 16 during cyclic nucleotide-dependent relaxation. Journal of Biological Chemistry 274 11344-11351.

Bradford MM 1976 A rapid and sensitive method for the quantification of microgram quantities of protein utilizing the principle of proteindye binding. Analytical Biochemistry 72 248-254.

Brophy CM, Dickinson M \& Woodrum D 1999 Phosphorylation of the small heat shock-related protein, HSP20, in vascular smooth muscles is associated with changes in the macromolecular associations of HSP20. Journal of Biological Chemistry 274 6324-6329.

Buhimschi C \& Garfield RE 1996 Uterine contractility as assessed by abdominal surface recording of electromyographic activity in rats during pregnancy. American Journal of Obstetrics and Gynecology 174 744-753.

Buhimschi C, Boyle MB, Saade GR \& Garfield RE 1998 Uterine activity during pregnancy and labour assessed by simultaneous recordings from the myometrium and abdominal surface in the rat. American Journal of Obstetrics and Gynecology 178 811-822.

Bukach OV, Seit-Nebi AS, Marston SB \& Gusev NB 2003 Some properties of human small heat shock protein Hsp20 (HspB6). European Journal of Biochemistry 271 291-302.

Challis JRG, Sloboda DM, Alfaidy N, Lye SJ, Gibb W, Patel FA, Whittle WL \& Newnham JP 2002 Prostaglandins and mechanisms of preterm birth. Reproduction 124 1-17.

Chow EH \& Marshall JM 1981 Effects of catecholamines on circular and longitudinal uterine muscle of the rat. European Journal of Pharmacology 76 157-165.

Ciocca DR, Oesterreich S, Chamness GC, McGuire WL \& Fuqua SA 1993 Biological and clinical implications of heat shock protein 27,000 (Hsp27): a review. Journal of the National Cancer Institute 85 $1558-1570$.

Dreiza CM, Brophy CM, Komalavilas P, Furnish EJ, Joshi L, Pallero MA, Murphy-Ullrich JE, von Rechenberg M, Ho YS, Richardson B, Xu N, Zhen Y, Peltier JM \& Panitch A 2005 Transducible heat shock protein 20 (HSP20) phosphopeptide alters cytoskeletal dynamics. FASEB Journal 19 261-263.

Fan G-C, Chu G, Mitton B, Song Q, Yuan Q \& Kranias EG 2004 Small heat-shock protein Hsp20 phosphorylation inhibits $\beta$-agonistinduced cardiac apoptosis. Circulation Research 94 1474-1482.

Fuchs LC, Giulumian AD, Knoepp L, Pipkin W, Dickinson M, Hayles C \& Brophy C 2000 Stress causes decrease in vascular relaxation linked with altered phosphorylation of heat shock proteins. American Journal of Physiology 279 R492-R498.

Girotti M \& Zingg HH 2003 Gene expression profiling of rat uterus at different stages of parturition. Endocrinology 144 2254-2265.

Gusev NB, Bogatcheva NV \& Marston SB 2002 Structure and properties of small heat shock proteins $(\mathrm{sHsp})$ and their interaction with cytoskeletal proteins. Biochemistry (Moscow) 67 613-623.
Gusev NB, Bukach OV \& Marston SB 2005 Structure, properties, and probable physiological role of small heat shock protein with molecular mass 20 kD (Hsp20, HspB6). Biochemistry (Moscow) 70 762-772.

Kato K, Ito H \& Inaguma Y 2002 Expression and phosphorylation of mammalian small heat shock proteins. In Progress in Molecular and Subcellular Biology, pp 129-150. Eds AP Arrigo \& WEG Muller. Berlin, Heidelberg: Springer-Verlag.

Kawarabayashi T \& Osa T 1976 Comparative investigations of alpha- and beta-effects on the longitudinal and circular muscles of the pregnant rat myometrium. Japanese Journal of Physiology 26 403-416.

Laemmli UK 1970 Cleavage of structural proteins during the assembly of the head of the bacteriophage T4. Nature 227 680-685.

Lye SJ, Nicholson BJ, Mascarenhas M, MacKenzie L \& Petrocelli T 1993 Increased expression of connexin-43 in rat myometrium during labor is associated with an increase in plasma estrogen:progesterone ratio. Endocrinology 132 2380-2386.

Lye SJ, Mitchell J, Nashman N, Oldenhof A, Ou R, Shynlova O \& Langille L 2001 Role of mechanical signals in the onset of term and preterm labor. In The Endocrinology of Parturition: Basic Science and Clinical Application, pp 165-178. Ed. R Smith. Basel, Switzerland: Karger.

MacPhee DJ \& Lye SJ 2000 Focal adhesion signaling in the rat myometrium is abruptly terminated with the onset of labour. Endocrinology 141 274-283.

Mlynarczyk M, Imamura T, Umezaki H, Kaushal KM, Zhang L \& Ducsay CA 2003 Long-term hypoxia changes myometrial responsiveness and oxytocin receptors in the pregnant ewe: Differential effects on longitudinal versus circular smooth muscle. Biology of Reproduction 69 1500-1505.

Oldenhof AD, Shynlova OP, Liu M, Langille BL \& Lye SJ 2002 Mitogenactivated protein kinases mediate stretch-induced c-fos mRNA expression in myometrial smooth muscle cells. American Journal of Physiology 283 C1530-C1539.

Osa T \& Katase T 1975 Physiological comparison of the longitudinal circular muscles of the pregnant rat uterus. Japanese Journal of Physiology 25 153-164.

Ou CW, Orsino A \& Lye SJ 1997 Expression connexin-43 and connexin-26 in the rat myometrium during pregnancy and labour is differentially regulated by mechanical and hormonal signals. Endocrinology 138 5398-5407.

Petropoulos H \& Skerjanc IS 2002 Beta-catenin is essential and sufficient for skeletal myogenesis in P19 cells. Journal of Biological Chemistry 277 15393-15399.

Rembold CM, Foster DB, Strauss JD, Wingard CJ \& Van Eyk JE 2000 cGMP-mediated phosphorylation of heat shock protein 20 may cause smooth muscle relaxation without myosin light chain dephosphorylation in swine carotid artery. Journal of Physiology 524 865-878.

Rembold CM, O'Connor M, Clarkson M, Wardle RL \& Murphy RA 2001 Selected contribution: HSP20 phosphorylation in nitroglycerin- and forskolin-induced sustained reductions in swine carotid media tone. Journal of Applied Physiology 91 1460-1466.

Rogerson PJ, Jamali M \& Skerjanc IS 2002 The c-terminus of myogenin, but not myoD, targets upregulation of mef2C expression. FEBS Letters 524 134-138.

Shynlova O, Mitchell JA, Tsampalieros A, Langille BL \& Lye SJ 2004 Progesterone and gravidity differentially regulate expression of extracellular matrix components in the pregnant rat myometrium. Biology of Reproduction 70 986-992.

Shynlova O, Oldenhof A, Dorogin A, Xu Q, Mu J, Nashman N \& Lye SJ 2006 Myometrial apoptosis: activation of the caspase cascade in the pregnant rat myometrium at midgestation. Biology of Reproduction 74 839-849.

Tabibzadeh S, Kong QF, Styaswaroop PG \& Babaknia A 1996 Heat shock proteins in human endometrium throughout the menstrual cycle. Human Reproduction 11 633-640. 
Tessier DJ, Komalavilas P, Panitch A, Joshi L \& Brophy CM 2003 The small heat shock protein (HSP) 20 is dynamically associated with the actin cross-linking protein actinin. Journal of Surgical Research $\mathbf{1 1 1}$ 152-157.

Tessier DJ, Komalavilas P, McLemore E, Thresher J \& Brophy CM 2004 Sildenafil-induced vasorelaxation is associated with increases in the phosphorylation of the heat shock-related protein 20 (HSP20). Journal of Surgical Research 118 21-25.

White BG, Williams SJ, Highmore K \& MacPhee DJ 2005 Small heat shock protein 27 (Hsp27) expression is highly induced in rat myometrium during late pregnancy and labour. Reproduction 129 115-126.
Williams SJ, White BG \& MacPhee DJ 2005 Expression of $\alpha 5$ integrin (Itga5) is elevated in the rat myometrium during late pregnancy and labor: Implication for development of a mechanical syncytium. Biology of Reproduction 72 1114-1124.

Received 23 October 2006

First decision 21 November 2006

Revised manuscript received 10 January 2007

Accepted 15 January 2007 